\title{
NEUROLOGICAL COMPLICATIONS OF ECLAMPSIA
}

\author{
Azhar Ali Khan'1, Pavan Kumar Singh², Reeta Singh ${ }^{3}$ \\ ${ }^{1}$ Associate Professor, Department of Medicine, BRD Medical College, Gorakhpur, Uttar Pradesh, India. \\ ${ }^{2}$ Associate Professor, Department of Medicine, BRD Medical College, Gorakhpur, Uttar Pradesh, India. \\ ${ }_{3}^{3}$ sssistant Professor, Department of Obstetrics and Gynaecology, BRD Medical College, Gorakhpur, Uttar Pradesh, India.
}

\section{ABSTRACT}

\section{BACKGROUND}

Eclampsia account for a third of maternal mortality in developing country. Eclampsia is a dreadful complication of hypertensive disorder of pregnancy and with high mortality and morbidity. The neurological manifestation of eclampsia consist of seizure and altered sensorium or coma on a background of pre-eclampsia. The major cause of mortality and morbidity includes encephalopathy, CVA and pulmonary oedema. Present study planned for evaluation of the neurological complications in patients of eclampsia.

\section{MATERIALS AND METHODS}

Twenty seven cases of complicated eclampsia who were admitted in Department of Gynae and Obst and Department of Medicine, BRD Medical College, Gorakhpur, were enrolled for the study. We selected all definite cases of eclampsia who did not recover neurologically within 48 hours of cessation of seizures. Detailed clinical examination was supported by investigations to assess renal, hepatic and haematological parameters along with electrophysiological and neuroimaging. Perinatal and maternal mortality was also recorded.

\section{RESULTS}

The age of patients ranges from to 18 to 38 years. Convulsions commonly last for 21-30 hrs. (13 patients, 48.14\%) followed by 1120 hrs. (5 patients, $18.51 \%$ ) and in only 2 patients (7.4\%) convulsions last for $>30$ hrs. Status epileptics was noted in $12 / 27$ (44.44\%) patients. Visual aura was noted in only $5 / 27(18.51 \%)$ patients. Foetal mortality was $33.33 \%(9 / 27)$ and maternal mortality was $18.51 \%$ (5/27).

EEG was abnormal in 15 (54.53\%) patients. The most common finding was diffuse slowing, which was noted in 8 (29.62\%) patients followed by hemispheric slowing and non-specific slowing.

CT/MRI was done in 24/27 patients. Abnormal CT was seen in 14 (58.33\%) patients. Out of them most common finding was leukoencephalopathy which was found in (8 patients, $33.33 \%$ ) followed by arterial infarct (13, 12.5\% patients), venous infarct in $4.16 \%$ patients and intracranial bleed in $4.16 \%$ patients.

\section{CONCLUSION}

A wide range of Neurological complications were found in the cases of eclampsia. These include status epilepticus, focal neurological deficits, cranial nerve involvement and vision loss along with convulsions leading to significant morbidity. In EEG, most common finding was diffuse slowing. Leukoencephalopathy and arterial infarcts were the most common findings in CT scan. MRI appears to be more sensitive than CT scan in detecting changes related to eclampsia. The lesions are hyperintense on T2 weighted images.

\section{KEYWORDS}

EEG - Electroencephalogram, CT - Computed Tomography, CVA - Cerebrovascular Accident, MRI - Magnetic Resonance Imaging.

HOW TO CITE THIS ARTICLE: Khan AA, Singh PK, Singh R. Neurological complications of eclampsia. J. Evolution Med. Dent. Sci. 2016;5(88):6529-6532, DOI: 10.14260/jemds/2016/1477

\section{BACKGROUND}

Ten percent of all pregnancies are complicated by hypertension. ${ }^{1}$ Eclampsia and preeclampsia account for about half of these cases worldwide and these conditions have been recognised and described for years despite the general lack of understanding of the disease. In the fifth century Hippocrates noted that headaches, convulsions and drowsiness were ominous signs associated with pregnancy. ${ }^{2}$

Financial or Other, Competing Interest: None.

Submission 13-10-2016, Peer Review 25-10-2016,

Acceptance 28-10-2016, Published 02-11-2016.

Corresponding Author:

Dr. Azhar Ali Khan,

Associate Professor

Department of Medicine,

BRD Medical College,

Gorakhpur-273013,

Uttar Pradesh, India.

E-mail:draak76@rediffmail.com

DOI: $10.14260 /$ jemds $/ 2016 / 1477$
In 1619, Varandaeus coined the term eclampsia in a treatise on gynaecology.

Eclampsia, which is considered a complication of severe preeclampsia, is commonly defined as new onset of grand mal seizure activity and/or unexplained coma during pregnancy or postpartum in a woman with signs or symptoms of preeclampsia.3,4 It typically occurs during or after the 20th week of gestation or in the postpartum period.

Eclampsia is a dreadful complication of hypertensive disorder of pregnancy and with high mortality and morbidity, particularly in the developing world. The major cause of mortality and morbidity includes encephalopathy, stroke and pulmonary oedema. Amongst these, the maximum morbidity is seen with neurological disorder.

Eclampsia is characterised by generalised tonic-clonic convulsions that develop in same woman with hypertension induced or aggravated by pregnancy. Eclampsia may be antepartum, intrapartum and postpartum. ${ }^{5}$ 


\section{MATERIALS AND METHODS}

Twenty seven cases of complicated eclampsia were registered in one year of period from July 2015 to July 2016 admitted in Department of Gynae and Obst. and Department of Medicine, BRD Medical College, Gorakhpur. We selected all definite cases of eclampsia who did not recover neurologically within 48 hours of cessation of seizures. Detailed clinical examination was supported by investigations to assess renal, hepatic and haematological parameters along with electrophysiological and neuroimaging as far as possible. As far as possible, the pathological mechanism responsible for this complication was concluded. Foetal and maternal mortality was noted.

\section{OBSERVATION}

\begin{tabular}{|c|c|c|}
\hline Profile & No. of Patients & Percentage (\%) \\
\hline Primigravida & 17 & $63 \%$ \\
\hline Multigravida & 10 & $37 \%$ \\
\hline $\begin{array}{c}\text { The age of patients } \\
\text { of eclampsia }\end{array}$ & & \\
\hline$<20$ & 2 & $7 \%$ \\
\hline $21-30$ & 21 & $77 \%$ \\
\hline $31-40$ & 4 & $15 \%$ \\
\hline \multicolumn{2}{|c|}{ Table 1. Demographical Profile in Eclampsia } \\
\hline
\end{tabular}

\begin{tabular}{|l|c|c|}
\hline \multicolumn{1}{|c|}{ Outcome } & $\begin{array}{c}\text { No. of } \\
\text { Patients }\end{array}$ & Percentage (\%) \\
\hline A) Perinatal Mortality & 9 & $33.33 \%$ \\
\hline B) Live Born & 18 & $66.66 \%$ \\
\hline C) Maternal Death & 5 & $18.51 \%$ \\
\hline \multicolumn{2}{|c|}{ Table 2. Maternal and Foetal Outcome } \\
\hline
\end{tabular}

\begin{tabular}{|c|c|c|}
\hline Duration (In hours) & $\begin{array}{c}\text { No. of } \\
\text { Patients }\end{array}$ & Percentage (\%) \\
\hline $01-10$ & 7 & $25.92 \%$ \\
\hline $11-20$ & 5 & $18.51 \%$ \\
\hline $21-30$ & 13 & $48.14 \%$ \\
\hline$>30$ & 2 & $7.4 \%$ \\
\hline \multicolumn{2}{|c|}{ Table 3. Features of Complications } \\
of Eclampsia Duration of Convulsion \\
\hline
\end{tabular}

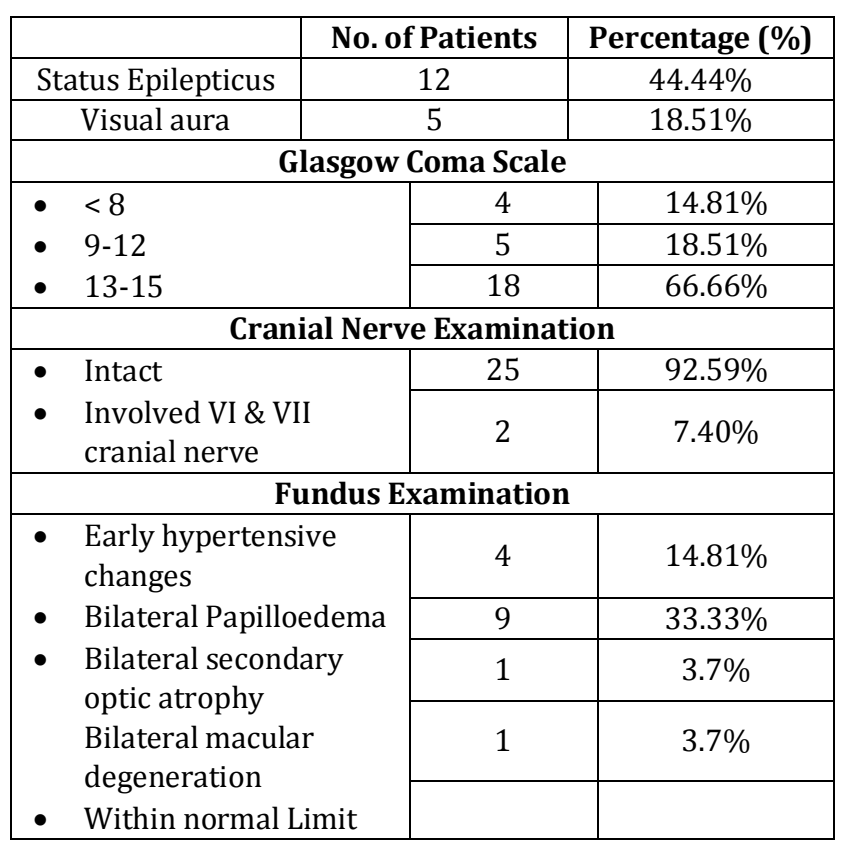

\begin{tabular}{|c|c|c|}
\hline \multicolumn{3}{|c|}{$\begin{array}{c}\text { Position of Limb, Deformity and } \\
\text { Focal Neurological Deficit } \\
\end{array}$} \\
\hline \multirow{4}{*}{$\begin{array}{ll} & \text { Hemiplegia } \\
\text { - } & \text { Monoplegia } \\
\text { - } & \text { Quadriplegia } \\
\text { - } & \text { Within normal limit } \\
\end{array}$} & 3 & $11.11 \%$ \\
\hline & 1 & $3.7 \%$ \\
\hline & 1 & $3.7 \%$ \\
\hline & 22 & $81.48 \%$ \\
\hline \multicolumn{3}{|c|}{ Deep Reflexes } \\
\hline \multirow{3}{*}{$\begin{array}{ll}\text { - } & \text { Diminished } \\
\text { - } & \text { Normal } \\
\text { - } & \text { Brisk }\end{array}$} & 18 & $66.66 \%$ \\
\hline & 3 & $11.11 \%$ \\
\hline & 6 & $22.22 \%$ \\
\hline \multicolumn{3}{|c|}{ Sign of Meningeal Irritation } \\
\hline \multirow{2}{*}{$\begin{array}{ll}\text { - } & \text { Present } \\
\text { - } & \text { Absent } \\
\end{array}$} & 3 & $11.11 \%$ \\
\hline & 24 & $88.88 \%$ \\
\hline \multicolumn{3}{|c|}{ Table 4. Neurological Status and Complications } \\
\hline
\end{tabular}

\begin{tabular}{|c|c|c|}
\hline Investigations & No. of Cases & Percentage (\%) \\
\hline \multicolumn{3}{|c|}{ Haemoglobin (mmHg) } \\
\hline \multirow{3}{*}{$\begin{array}{ll}\bullet & <7.0 \\
\bullet & 7.1-11.0 \\
- & >11.0\end{array}$} & 3 & 11.11 \\
\hline & 12 & 44.44 \\
\hline & 12 & 44.44 \\
\hline \multicolumn{3}{|c|}{ Total Leukocyte Count (cmm3/hpf) } \\
\hline \multirow{3}{*}{$\begin{array}{ll}\text { - } & <4000 \\
\text { - } & 4001-11000 \\
\text { - } & >11000\end{array}$} & 3 & 11.11 \\
\hline & 13 & 48.14 \\
\hline & 11 & 40.74 \\
\hline \multicolumn{3}{|c|}{ Differential Leukocyte Count } \\
\hline \multicolumn{3}{|c|}{ Polymorph } \\
\hline \multirow{2}{*}{$\begin{array}{ll}\text { - } & 40-70 \\
\text { - } & >70 \\
\end{array}$} & 5 & 18.51 \\
\hline & 22 & 81.48 \\
\hline \multicolumn{3}{|c|}{ Lymphocytes } \\
\hline - $<45$ & 15 & 55.55 \\
\hline - $\quad>45$ & 12 & 44.44 \\
\hline \multicolumn{3}{|c|}{ ESR (mm) } \\
\hline \multirow{2}{*}{$\begin{array}{ll}- & <15 \\
- & >15\end{array}$} & 10 & 37.03 \\
\hline & 17 & 62.97 \\
\hline \multicolumn{3}{|c|}{ Platelet Count } \\
\hline \multirow{4}{*}{$\begin{array}{ll} & 0.5-1.0 \text { lack } \\
\text { - } & 1.0-1.5 \text { lack } \\
\text { - } & 1.6-2.0 \text { lack } \\
\text { - } & >2.0 \text { lack } \\
\end{array}$} & 7 & 25.92 \\
\hline & 8 & 29.62 \\
\hline & 6 & 22.22 \\
\hline & 6 & 22.22 \\
\hline \multicolumn{3}{|c|}{ Serum Creatinine } \\
\hline \multirow{2}{*}{$\begin{array}{ll}\text { - } & \text { Normal } \\
\text { - } & \text { Abnormal } \\
\end{array}$} & 7 & 25.92 \\
\hline & 20 & 74.07 \\
\hline \multicolumn{3}{|c|}{ Serum Uric Acid } \\
\hline \multirow{2}{*}{$\begin{array}{ll}- & \text { Normal } \\
\text { - } & \text { Abnormal } \\
\end{array}$} & 8 & 29.62 \\
\hline & 19 & 70.34 \\
\hline \multicolumn{3}{|c|}{ Serum Bilirubin } \\
\hline \multirow{2}{*}{$\begin{array}{ll}\text { - } & \text { Normal } \\
\text { - } & \text { Abnormal } \\
\end{array}$} & 16 & 59.25 \\
\hline & 11 & 40.74 \\
\hline \multirow{3}{*}{$\begin{array}{ll}\text { - } & \text { Normal } \\
\text { - } & \text { Abnormal }\end{array}$} & \multicolumn{2}{|l|}{ SGPT } \\
\hline & 16 & 59.25 \\
\hline & 11 & 40.74 \\
\hline \multicolumn{3}{|c|}{ SGOT } \\
\hline \multirow{2}{*}{$\begin{array}{ll}\text { - } & \text { Normal } \\
\text { - } & \text { Abnormal }\end{array}$} & 16 & 59.25 \\
\hline & 11 & 40.74 \\
\hline \multicolumn{3}{|c|}{ Serum Alkaline Phosphatase } \\
\hline \multirow{2}{*}{$\begin{array}{ll}\text { - } & \text { Normal } \\
\text { - } & \text { Abnormal } \\
\end{array}$} & 10 & 37.03 \\
\hline & 17 & 62.96 \\
\hline
\end{tabular}




\begin{tabular}{|c|c|c|}
\hline EEG Findings & $\begin{array}{c}\text { No. of } \\
\text { Patients }\end{array}$ & $\begin{array}{c}\text { Percentage } \\
\text { (\%) }\end{array}$ \\
\hline Within Normal Limit & 12 & 44.44 \\
\hline Diffuse Slowing & 8 & 29.62 \\
\hline Hemispheric Slowing & 4 & 14.81 \\
\hline Non-Specific Slowing & 2 & 7.45 \\
\hline $\begin{array}{c}\text { Burst of Slow Wave in } \\
\text { Periods }\end{array}$ & 1 & 3.7 \\
\hline \multicolumn{2}{|c|}{$\begin{array}{c}\text { Table 6. Electrophysiological } \\
\text { Feature (EEG) in Eclampsia }\end{array}$} \\
\hline
\end{tabular}

\begin{tabular}{|c|c|c|}
\hline CT Findings & $\begin{array}{c}\text { No. of } \\
\text { Patients }\end{array}$ & $\begin{array}{c}\text { Percentage } \\
\text { (\%) }\end{array}$ \\
\hline Within Normal Limit & 10 & 33.33 \\
\hline Leukoencephalopathy & 8 & 33.33 \\
\hline Arterial Infarct & 3 & 12.5 \\
\hline Venous Infarct & 1 & 4.16 \\
\hline $\begin{array}{c}\text { Intracranial } \\
\text { Haemorrhage }\end{array}$ & 1 & 4.16 \\
\hline $\begin{array}{c}\text { Parieto-occipital Cerebral } \\
\text { Oedema }\end{array}$ & 1 & 4.16 \\
\hline $\begin{array}{c}\text { Table 7. Radiological Feature in } \\
\text { Eclampsia CT Head (N = 24) }\end{array}$ \\
\hline
\end{tabular}

\section{RESULTS}

The age of patients ranges from 18 to 38 years. Most of the eclampsia patients were of 21-30 years (21 patients, 77\%). Only 2 patients $(7 \%)$ were $<20$ years of age and 4 patients (15\%) were > 30 years; $63 \%$ (17) patients were primary gravida and their age was between 20 and 30 years; 10 patients (37\%) were multigravida (Table 1).

Foetal mortality was $33.33 \%(9 / 27)$ and maternal mortality was $18.51 \%(5 / 27)$ (Table 2$)$.

Convulsions commonly last for 21-30 hrs. (13 patients, $48.14 \%$ ) followed by $11-20 \mathrm{hrs}$. (5 patients, $18.51 \%$ ) and in only 2 patients $(7.4 \%)$ convulsions last for $>30 \mathrm{hrs}$. Status epilepticus was noted in $12 / 27$ (44.44\%) patients. Visual aura in only $5 / 27$ (18.51\%) patients (Table 3 ).

During neurological examination on Glasgow coma scale, 4 $(14.85 \%)$ patients were of $<8,5(18.51 \%)$ patients were between 9 and 12 , and $18(66.66 \%)$ patients were between 13 and 15 (Table 4).

Cranial nerves were involved in $2(7.40 \%)$ patients. Out of these in one patient VI cranial nerve was involved and in other VII cranial nerve (Table 4).

Papilloedema was present in 15 (55.54\%) patients. While bilateral macular degeneration was present in only $1(3.7 \%)$ patient and bilateral optic atrophy was found in 1 patient (3.7\%) (Table 4).

Focal neurological deficits were seen in 5 (18.51\%) patients, in which $3(11.11 \%)$ patients had hemiplegia, 1 had monoplegia and the other one was quadriplastic (Table 4).

Reflexes were diminished in majority $(18 / 27,66.66 \%)$ of patients. Hyperreflexia was seen in $6 / 27(22.22 \%)$ of the patients. Babinski sign was positive in 11 (39\%) of patients (Table 4). Symptoms of neurological irritation were seen in $3 / 27$ (11.11\%) of the patients.

Investigations reveal severe anaemia in 3 (11.11\%) patients, leukopenia in $3(11.11 \%)$, while leukocytosis in 11 $(40.74 \%)$ patients. Polymorphonuclear leukocytosis was seen in $22(81.48 \%)$ patients. ESR was raised in $17(62.97 \%)$ patients. Thrombocytopenia was found in 15 (55.54\%) patients. Serum creatinine was raised in 20 patients $(74.07 \%)$ and uric acid was raised in 19 (70.37\%) patients. Liver profile (S. Bilirubin, SGPT and SGOT) was raised in 11 patients $40.74 \%$ (Table 5).

EEG was abnormal in 15 (54.53\%) patients. The most common finding was diffuse slowing, which was noted in 8 (29.62\%) patients followed by hemispheric slowing and nonspecific slowing (Table 6).

CT was done in 24/27 patients. Abnormal CT was seen in $14(58.33 \%)$ patients. Out of them, most common finding was leukoencephalopathy which was found in (8 patients, 33.33\%) followed by arterial infarct $(13,12.5 \%$ patients), venous infarct in $4.16 \%$ patients and intracranial bleed in $4.16 \%$ patients (Table 7).

\section{DISCUSSION}

Neurological complications of eclampsia include psychosis, raised intracranial pressure, coma and cerebrovascular accidents presenting as focal deficits, e.g. cortical blindness, aphasia and limb weakness. In the present series, 5 (18.5\%) patients had focal deficits. The mechanisms leading to the development of convulsions, coma and focal deficits in eclamptic patients include a combination of many factors like cerebral oedema, ischaemia, haemorrhage, transient vasospasm, Disseminated Intravascular Coagulation (DIC) and metabolic alteration. Since angiography was not performed, the contribution of vasospasm remains unknown.4,5

Although, the EEG pattern during eclampsia is usually a diffuse slow activity (Theta or delta range), sometimes with focal slowing and occasion paroxysmal activity, none of these findings are pathognomonic of eclampsia because similar patterns may be seen in hypoxia, renal disease, hypocalcaemia and water intoxication. Donaldson claimed that eclamptic convulsions are secondary to cortical lesions developing after a sudden increase in blood pressure in a previously normotensive patient. He attributed the cortical lesion to failure of cerebral autoregulation resulting in rupture of capillary junctions with leakage of both plasma and red blood cells. On the other hand, Brusse IA et $\mathrm{al}^{6}$ and Sibai et $\mathrm{al}^{4}$ did not find any correlation between EEG changes and the degree of blood pressure elevation. ${ }^{4,7}$ Sibai et al reported EEG diffuse slowing followed by focal slowing and intermittent diffuse/focal spike activity in review of previous studies $(\mathrm{n}=84)$. Thomas et al found an abnormal interictal EEG in $80 \%$ of patients. In our studies 18 of the 32 (56\%) patients had an abnormal EEG with similar distribution of abnormal findings.4,7 A similar qualitative and quantitative EEG abnormality has also been in Brusse IA. ${ }^{8}$ The persistence of an abnormal EEG 1 week after delivery in 31 of 46 patients studied is in consonance with the syndrome of post-partum eclampsia. In present study, EEG abnormality seen in 15 (54.53\%) patients, in which common abnormality diffuse slowing $8(29.62 \%)$ patients followed by hemispheric slowing in $4(14.81 \%)$ patients and non-specific slowing in $2(7.4 \%)$ patients.

There have been variable reports concerning the incidence of CT findings in women with eclampsia. Sibai et al ${ }^{4}$ reported no CT abnormality in series of 65 cases. On the other end of the spectrum, more than $70 \%$ of patients had abnormalities on CT scanning in some studies. This diversity is due to different selection criteria employed by various investigators. Sibai et al included all cases of eclampsia presenting to them, whereas Richards et al studied the CT findings in 20-192 patients who 
had severe eclampsia and remained in coma for more than 6 hours. Brown and Associates (1988) noted that the highest incidence of abnormal CT findings (50\%) was seen during the last year of study.9,10,11 This increased sensitivity was attributed to improved "fourth generation" imaging generation imaging equipment. In another study $(n=44)$ where cranial CT scans were done within 24 hours of seizures, $31 \%$ had an abnormal scan. In a review, Thomas et al noted abnormal CT scan findings in $57 \%$ cases. In the present study, CT scan was done in 24 (88.88\%) patients. Abnormal CT scan was seen in 14 (58.33\%) patients, in which most common findings was leukoencephalopathy in $8(33.33 \%)$ patients followed by arterial infarct in $3(12.5 \%)$ patients, whereas venous infarct and intracranial haemorrhage were noted in one patient each. Various CT scan abnormalities ${ }^{8,6,12}$ in eclamptic patients include patchy and diffuse cerebral oedema, loss of cortical sulci and decreased ventricular size, hydrocephalus, intraventricular and parenchymal haemorrhages and infarcts involving the cortex and basal ganglia. ${ }^{13,14}$ MRI appears to be more sensitive than CT scan in detecting changes related to eclampsia. The lesions are hyperintense on $\mathrm{T} 2$ weighted images.

The perinatal mortality rate reported varies in different series. In Yadav et al, perinatal mortality was $14.8 \%$ and in $\mathrm{R}$ Sachan et al total perinatal mortality was $21.19 \%$. In our study, perinatal mortality was found to be $33.33 \%$.

Maternal mortality in $\mathrm{R}$ Sachan et al was $2.8 \%$ of hypertensive ANC patients, all of which were eclampsia group patients. Ratan Das et al found $4.96 \%$ mortality among the patients of preeclampsia and eclampsia. In our study, maternal mortality was $18.5 \%$ patients.

\section{CONCLUSION}

A wide range of neurological complications were found in the cases of eclampsia. These include status epilepticus, focal neurological deficits, cranial nerve involvement and vision loss along with convulsions leading to significant morbidity. In EEG, most common finding was diffuse slowing. Leukoencephalopathy and arterial infarcts were the most common findings in CT scan. MRI appears to be more sensitive than CT scan in detecting changes related to eclampsia. The lesions are hyperintense on $\mathrm{T} 2$ weighted images.

\section{ACKNOWLEDGEMENT}

We express our sincere thanks and gratitude to our assistant, associate professor and PG residents for valuable support. I express my sincere thanks to Department of Obstetrics and Gynaecology Department for providing eclamptic patients. I am also thankful to all paramedical staff for technical support.

\section{REFERENCES}

1. Horsager $R$, Roberts $S$, Rogers $V$, et al. Hypertensive disorder. Williams obstetrics. 24th edn. McGrawHill 2014:p.728.
2. Dolea C, AbouZahr C. Global burden of hypertensive disorders of pregnancy in the year 2000. Evidence and information for policy (EIP). Geneva, Switzerland: World Health Organization 2003.

3. Khan KS, Wojdyla D, Say L, et al. WHO analysis of causes of maternal death: a systematic review. The Lancet 2006;367(9516):1066-1074.

4. Sibai BM, Spinnato JA, Watson DL, et al. Effect of magnesium sulphate on electroencephalographic findings in preeclampsia-eclampsia. Obs and Gyne 1984;64(2):216220.

5. World Health Organization. The world health report 2005: make every mother and child count. Geneva, Switzerland: World Health Organization 2005.

6. Brusse IA, Peters NC, Steegers EA, et al. Electroencephalography during normotensive and hypertensive pregnancy: a systematic review. Obstet Gynecol Surv 2010;65(12):794-803.

7. Thornton C, Dahlen H, Korda A, et al. The incidence of preeclampsia and eclampsia and associated maternal mortality in Australia from population-linked data sets: 2000-2008. American Journal of Obstetrics \& Gynecology 2013;208(6):476.e1-476.e5.

8. Basso 0, Rasmussen S, Weinberg CR, et al. Trends in fetal and infant survival following preeclampsia. Journal of the American Medical Association 2006;296(11):1357-1362.

9. Cantwell R, Clutton-Brock T, Cooper G. Saving mothers lives: reviewing maternal deaths to make motherhood safer: 2006-2008. The eighth report of the confidential enquiries into maternal deaths in the United Kingdom. British Journal of Obstetrics and Gynaecology 2011; 118(suppl 1):1-203.

10. Mackay AP, Berg CJ, Atrash HK. Pregnancy-related mortality from preeclampsia and eclampsia. Obstetrics \& Gynecology 2001;97(4):533-538.

11. Aukes AM, Wessel I, Dubois AM, et al. Self-reported cognitive functioning in formerly eclamptic women. American Journal of Obstetrics \& Gynecology 2007; 197(4):365.e1-365.e6.

12. Yadav S, Saxena U, Yadav R, et al. Hypertensive disorders of pregnancy and maternal and foetal outcome: a case controlled study. J Indian Med Assoc 1997;95(10): 548-551.

13. Sachan R, Patel ML, Sachan P, et al. Outcome in hypertensive disorders of pregnancy in the north Indian population. Int J Womens Health 2013;5:101-108

14. Thomas SV, Somnathan N, Radhakumari R. Interictal EEG changes in eclampsia. Electro-encephalogr Clin Neurophysilol 1995;94(4):271-275. 